5 Brusasco V, Pellegrino R, Rodarte JR. Vital capacities in acute and chronic airway obstruction: dependence on flow and volume histories Eur Respir J 1997; 10: 1316-1320.

6 Paoletti P, Pistelli G, Fazzi P, et al. Reference values for vital capacity and flow-volume curves from a general population study Bull Eur Physiopathol Respir 1986; 22: $451-459$.

\title{
Antibiotics for chronic bronchitis: a meta-analysis that speaks only four languages
}

\section{To the Editors:}

We have read with interest the meta-analysis by SIEMPOS et al. [1] evaluating the use of different antibiotics for exacerbations of chronic bronchitis. We are puzzled by the criteria used to select the studies that were included in the analysis. The authors utilised a well-established methodology and quality criteria for the selection of randomised clinical trials, but only studies written in English, French, German or Italian were included in the analysis [1]. English is now accepted as the most common language in scientific literature; however, there is an increasing number of peer-reviewed scientific journals written in languages other than English that have published clinical studies with data relevant to the issue of this metaanalysis. In fact, among the top 25 respiratory journals ranked by impact factor there is one published in Spanish with an impact factor of 1.401 [2].

It is not clear to us why SIEMPOs et al. [1] have reviewed articles written in French, German and Italian and excluded the others. Most of the indexed non-English journals include English abstracts with information that may help verify the quality of the study. If the study proved to be scientifically important, there are individuals, organisations and companies that provide translation services that would help make the overall goals more accurate.

In the article by SIEMPOS et al. [1], five studies were excluded due to language selection. Considering that in one of the comparisons, conclusions were drawn based on only four studies, the inclusion of one or more of the excluded studies could have impacted on the final results. Furthermore, the authors did not provide references for the publications that were excluded. Provided with this information, the interested reader could compare the results of the excluded works with those of the studies included in the meta-analysis and verify whether this arbitrary exclusion could have potentially biased the results.

Therefore, we believe that the European Respiratory Journal should not accept exclusion criteria beyond those that are strictly based on science. The exclusion of studies based on the language of publication is simply unacceptable.

\section{Miravitlles*, B. Celli" and A. Anzueto}

*Dept of Pneumology, Institut Clínic del Tòrax (IDIBAPS), Hospital Clínic, Barcelona, Spain. "St Elizabeth's Medical
Center, Brighton, MA. ${ }^{\top}$ Health Science Center, University of Texas, San Antonio, TX, USA.

\section{STATEMENT OF INTEREST}

None declared.

\section{REFERENCES}

1 Siempos II, Dimopoulos G, Korbila IP, Manta K, Falagas ME. Macrolides, quinolones and amoxicillin/clavulanate for chronic bronchitis: a meta-analysis Eur Respir J 2007; 29: 1127-1137.

2 ISI Web of Knowledge. Journal citation reports. http:// portal.isiknowledge.com/portal.cgi. Date last accessed: June $12,2007$.

DOI: $10.1183 / 09031936.00071607$

From the authors:

We would like to thank M. Miravitlles and co-workers for their interest in our meta-analysis [1]. They commented on our choice not to include randomised controlled trials (RCTs) in the meta-analysis that were written in languages other than English, French, German or Italian. In addition, they criticised the fact that the references of the excluded RCTs were not available. We welcome the letter by our respectable colleagues and would like to respond to the points they raised.

We would like to emphasise that our research team's policy regarding the reporting of meta-analyses is to provide the references of all excluded trials to secure transparency and reproducibility of our work. For instance, in another metaanalysis performed by our team that has been recently published in the European Respiratory Journal (ERJ), we have done so [2]. However, for the contribution under discussion, we would have to have provided 139 additional references (i.e. the number of the studies that were omitted for various reasons as explained in the relevant figure of our article); we considered that this number was probably excessive, given the space limitations of the ERJ.

We carefully reviewed the abstracts of the five RCTs that were excluded due to language restrictions [3-7]. None of them provided data relevant to the subject of our meta-analysis (namely the comparison of macrolides, quinolones and amoxicillin/clavulanate for the treatment of patients with 
acute bacterial exacerbations of chronic bronchitis). Thus, the findings of our meta-analysis would not be different if we did not use language restrictions.

We would also like to point out that a considerable proportion of meta-analyses that are published in high-impact factor journals include only English language studies. In addition, in the Quality Of Reporting Of Meta-analyses (QUOROM) statement, language-inclusive meta-analyses are encouraged, but restriction in study selection based on the language of publication is not considered unacceptable. Besides, a recent comprehensive study on the topic revealed that "for conventional medicine interventions, language-restricted systematic reviews, compared with language-inclusive ones, did not introduce biased results, in terms of estimates of intervention effectiveness" and concluded that "language restrictions do not change the results of conventional medicine systematic reviews" [8]. Apparently, the Editors of the ERJ have been aware of this evidence and, given the clinical importance of our meta-analysis, decided to publish it after the appropriate peer review.

Nevertheless, we certainly share the reasonable concerns of our colleagues regarding the penetration of the English language in modern research. In fact, we are very sensitive regarding this issue as well and, moreover, we have already commented on it [9]. In addition, we have also compiled a list of a number of non-English language world databases of summaries of articles in the biomedical fields with the hope that such databases might contain data useful for researchers and clinicians [10].

\section{I.I. Siempos*, G. Dimopoulos*,\# and M.E. Falagas ${ }^{*},++$}

*Alfa Institute of Biomedical Sciences (AIBS), and "Intensive Care Unit, Attikon University Hospital, and "Dept of Medicine, Henry Dunant Hospital, Athens, Greece. ${ }^{+}$Dept of Medicine, Tufts University School of Medicine, Boston, MA, USA.

\section{STATEMENT OF INTEREST}

None declared.

\section{REFERENCES}

1 Siempos II, Dimopoulos G, Korbila IP, Manta K, Falagas ME. Macrolides, quinolones and amoxicillin/ clavulanate for chronic bronchitis: a meta-analysis. Eur Respir J 2007; 29: 1127-1137.

2 Siempos II, Vardakas KZ, Manta KG, Falagas ME. Carbapenems for the treatment of immunocompetent adult patients with nosocomial pneumonia. Eur Respir J 2007; 29: 548-560.

3 Gómez J, Baños V, Simarro E, et al. [Prospective, comparative study (1994-1998) of the influence of short-term prophylactic treatment with azithromycin on patients with advanced COPD.] Rev Esp Quimioter 2000; 13: 379-383.

4 Alvarez Gutiérrez FJ, Soto Campos G, del Castillo Otero D, et al. [A randomized comparative study of 3 days of azithromycin treatment and 10 days of cefuroxime treatment in exacerbations in patients with chronic obstructive pulmonary disease.] Med Clin (Barc) 1999; 113: 124-128.

5 Sawae Y, Kashiwagi S, Kumagai Y, et al. [Clinical studies on the utility of ofloxacin for lower respiratory infections.] Jpn J Antibiot 1991; 44: 48-57.

6 Faber M, Jahnz-Rózyk K, Targowski T, Mamełka B. [Comparative analysis of the effectiveness and costs of azithromycin and cefoperazone treatment of patients during COPD exacerbation.] Pol Merkur Lekarski 2003; 14: 36-38.

7 Haanaes OC, Hansen G, Holten K, Vigander T. [Antibiotics in chronic bronchitis.] Tidsskr Nor Laegeforen 1980; 100: 1902-1904.

8 Pham B, Klassen TP, Lawson ML, Moher D. Language of publication restrictions in systematic reviews gave different results depending on whether the intervention was conventional or complementary. J Clin Epidemiol 2005; 58: 769-776.

9 Falagas ME, Fabritsi E, Chelvatzoglou FC, Rellos K. Penetration of the English language in science: the case of a German national interdisciplinary critical care conference. Crit Care 2005; 9: 655-656.

10 Falagas ME, Giannopoulou KP, Issaris EA, Spanos A. World databases of summaries of articles in the biomedical fields. Arch Intern Med 2007; 167: 1204-1206. 